\title{
DESENVOLVIMENTO DE PROTÓTIPOS DE MOBILIÁRIO URBANO COM SUBPRODUTO DE MADEIRA SERRADA DE EUCALIPTO
}

Tomás Queiroz Ferreira Barata

Universidade Estadual "Júlio de Mesquita

Filho" - UNESP, Campus Bauru.

barata@faac.unesp.br

Ingo Cescatto Germer

Universidade Estadual "Júlio de Mesquita

Filho" - UNESP, Campus Bauru.

ingocgermer@hotmail.com

\author{
Mirela Riquena De Giuli \\ Universidade Estadual "Júlio de Mesquita \\ Filho" - UNESP, Campus Bauru. \\ mirela_rgiuli@outlook.com \\ Paulo Manuel Cadete Ferrão \\ Instituto Superior Técnico - Lisboa, Portugal \\ ferrao@tecnico.ulisboa.pt
}

Resumo: O design tem um papel crucial no atendimento das demandas da sociedade e na sinalização de tendências para as transformações culturais e sociais, com destaque para a preocupação com a sustentabilidade global e a proteção do meio ambiente. É de grande importância a função do designer no sentido de contribuir para a concepção, desenvolvimento e produção de produtos inovadores que incorporem conceitos de sustentabilidade no seu ciclo de vida. Este artigo tem como objetivo apresentar o processo de desenvolvimento de protótipos de mobiliário urbano com subproduto de madeira serrada de eucalipto com ênfase na aplicação de conceitos de sustentabilidade visando à qualificação de espaços públicos. A metodologia da pesquisa divide-se em: caracterização do material, procedimentos relacionados à atividade projetivae análise das etapas produtivas de protótipos. Como resultados são apresentados dados sobre as características do subproduto "costaneira", o processo de desenvolvimento de projeto e as etapas de produção de dois protótipos de mobiliários urbanos.

Palavra-chave: Mobiliário urbano, madeira, eucalipto, sustentabilidade, design.

\begin{abstract}
The design have a crucial importance about the demands of society and signaling trends to the cultural and social changes, especially the concern with global sustainability and environmental protection. It is of great importance to the role of the designer in order to contribute to the design, development and production of innovative products incorporating sustainability concepts in their life cycle. This article aims to present the urban furniture prototype development process using sub-product of lumber eucalyptus with emphasis on the application of sustainability concepts to qualify public spaces. The research methodology is divided into: characterization of the material, procedures related to projective activity
\end{abstract}


and analysis of the production stages of prototypes. As the results, are presented data about the sub-product characteristics, the project development process and the stages of production of two urban furniture prototypes.

Keywords: Furniture, wood, eucalyptus, sustainability, design.

\section{INTRODUÇÃO}

Uma das demandas atuais da sociedade refere-se à produção e ao consumo responsável de produtos inovadores que incorporem conceitos de sustentabilidade no seu ciclo de vida. O Conselho Internacional de Sociedades de Design Industrial (ICSID, 2013) considera o design um fator crucial para transformações culturais e econômicas, propondo assim, uma definição de design mais abrangente, mais comprometida com as atuais demandas econômicas, sociais e ambientais, como por exemplo, a preocupação com a sustentabilidade global e a proteção do meio ambiente.

Segundo Pazmino (2007), design sustentável "é um processo mais abrangente e complexo que contempla que o produto seja economicamente viável, ecologicamente correto e socialmente equitativo". Ainda segundo a autora, esta vertente do design se propõe a não prejudicar o equilíbrio ambiental e garantir este mesmo equilíbrio para futuras gerações.Ferrão (2009) destaca que o modo de vida de uma sociedade se caracteriza pela forma como estautiliza e transforma os recursos naturais disponíveis em materiais e produtos e, consequentemente, gera e descarta resíduos no meio ambiente. Manzini e Vezzoli (2002) apontam que para o desenvolvimento de um design sustentável é necessário que haja diminuição de consumo e redução de fabricação dos produtos materiais.

No processo de industrialização da madeira de eucalipto, o desperdício pode ultrapassar $50 \%$ do volume da tora. Na etapa de beneficiamento ou desdobro primário, que visa separar a madeira útil do resíduo, ocorre à remoção das quatro costaneiras, tábuas com uma face plana e outra curvilínea - que remetem a porção externa da árvore/tora onde se encontra o alburno e parte do cerne. Este material não é utilizado como madeira serrada por duas razões principais: a presença do alburno, mais suscetível ao ataque de organismos xilófagos e por sua forma atípica, fora dos padrões e das técnicas usuais de desdobro.

Considerando a importância do design como fator crucial para as transformações culturais e sociais, e tendo em vista a preocupação com a preservação ambiental e as consequências dos resíduos gerados em grande quantidade pelas indústrias, esta pesquisa procurou além de apresentar algumas das possibilidades de agregar valor a um material de descarte, qualificar espaços públicos com o desenvolvimento de protótipos adequados às demandas dos usuários.GIL (2011) sustenta a importância dessa qualificação ao afirmar que"notado a crescente demanda por espaços públicos que ofereçam qualidade aos seus usuários, se torna cada vez mais importante pensar e aplicar os conceitos presentes no campo da arquitetura, design e engenharia. É de conhecimento que o ambiente influencia diretamente seu público, seja através das cores, cheiros, texturas e diversos outros fatores, sendo assim é impossível dissociar o público do seu espaço. Com um índice cada vez maior de regiões consideradas urbanas, indubitavelmente, a qualificação dos locais considerados 
comuns, públicos ou urbanos já que existe uma constante demanda de usuários por esses espaços e equipamentos".

Sendo assim, a pesquisa apresentada neste artigo visa agregar valor a um dos subprodutos da madeira serrada, no caso, peças de costaneira de eucalipto, com intuito de contribuir para a qualificação de praças, parques e espaços públicos em geral, através da experimentação projetiva de mobiliários com a aplicação de conceitos e teorias do design sustentável.

\section{MATERIAIS E MÉTODOS}

O presente artigo apresenta uma metodologia descritiva com a investigação projetiva e experimentação produtiva em laboratório, que resultou em dois protótipos físicos de mobiliário urbano. A seguir são apresentados os materiaise equipamentos empregados na pesquisa e os procedimentos metodológicos adotados, divididos em caracterização do material, atividade projetiva e produção dos protótipos.

\subsection{Materiais}

Matéria-primautilizada no desenvolvimento dos protótipos:A matéria-prima empregada na produção dos protótipos foi o subproduto comumente conhecido como costaneira da madeira serrada de eucalipto da espécie Corymbia citriodora(figura 1). Por se tratar da porção externa da tora, a costaneira apresenta características singulares como: formato, espessura, comprimento, nós, presença de brocas e cupins, podres, empenamento, encanoamento e rachaduras. Sendo assim, foram definidos critérios como medidas mínimas e máximas e qualidade das peças que ofereciam potencial para serem utilizadas na produção dos protótipos (figura 2).
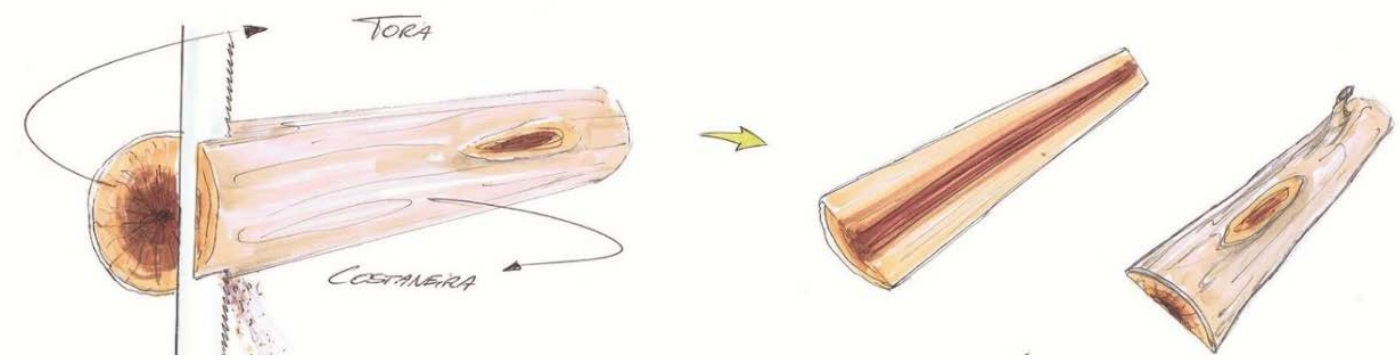

Figura 1- Subproduto costaneira é obtido no primeiro corte da tora.

Fonte: Elaborado pelo autor, com base na pesquisa realizada.

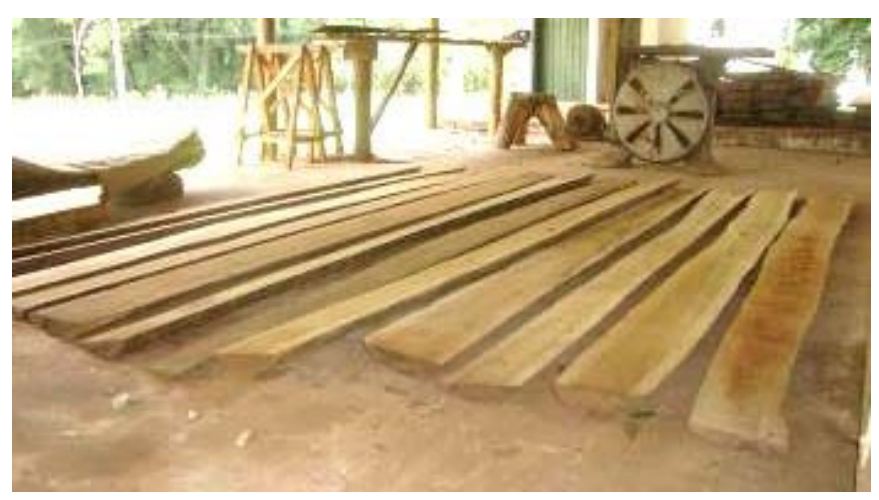

Figura 2- Costaneirasselecionadas para o desenvolvimento dos protótipos.

Fonte: Elaborado pelo autor, com base na pesquisa realizada. 
Materiais empregados no desenvolvimento do projeto e na produção: Papel sulfite; Marcadores; Nankin; Lápis grafite; Borracha; Parafusos autoatarraxantes; Cola para madeira; Cavilhas feitas de eucalipto; Barras metálicas provenientes de feixes de molas de suspensão; Lixa para madeira e Stainà base d'água.

Equipamentos utilizados no desenvolvimento da pesquisa:SoftwareSolidWorks 2013; Martelo; Serrote; Goniômetro; Esquadro; Serra circular; Lixadeiras; Furadeira horizontal; Parafusadeira; Plaina desempenadeira; Esquadrejadeira; Esmeril de bancada; Esmerilhadeira Manual; Solda MIG;Policorte; Sargento de haste ede rosca.

\subsection{Procedimentos metodológicosda pesquisa \\ Caracterização do material}

Para selecionar as costaneiras, foi realizada uma pré-avaliação do lote total buscando agilizar a escolha das peças que realmente se mostravam utilizáveis. Após esta pré-avaliação, foi desenvolvida uma planilha a fim de facilitar a avaliação e a seleção daquelas que apresentaram potencial para desenvolvimento dos protótipos físicos. Sendo assim, as peças foram separadas, numeradas e analisadas minuciosamente permitindo a coleta das dimensões básicas e respectivas particularidades que apresentam.

\section{Procedimentos das atividades projetivas}

As atividades de desenvolvimento de projeto se organizaram da seguinte forma:

a) Pesquisa de similares: Foram observados diversos similares de mobiliário urbano a fim de aumentar o repertório da pesquisa e contribuir com a geração de novas alternativas;

b) Definição de diretrizes sustentáveis: Foram definidas diretrizes para aplicação de conceitos de sustentabilidade do projeto através de revisão literária.

c) Geração de alternativas: Foram desenvolvidas propostas como a alternativa de aplicação do subproduto, utilizando técnicas livres de sketch e ilustração.

d) Seleção de alternativas: Foram selecionadas as propostas que teriam melhor aplicação dos conceitos da pesquisa, como, por exemplo, união de peças de costaneira para a formação de faces e a posterior união das faces formadas.

e) Modelagem virtual: Foi utilizado umsoftwarepara a modelagem dos protótipos a serem produzidos, possibilitando uma melhor compreensão do produto final bem como a geração do projeto executivo.

\section{Procedimentos das atividades produtivas}

As atividades produtivas para o desenvolvimento dos dois protótipos se dividiram em:

a)Seleção da matéria-prima: Previamente foram analisadas as particularidades (broca, cupim, podre, rachadura, variação dimensional, entre outras) de cada costaneira e em seguida foram selecionadas aquelas que atenderiam às demandas da pesquisa.

b)Transformação dos materiais: Selecionadas as costaneiras que apresentaram potencial para a aplicação na pesquisa, deu-se início à transformação do material utilizando maquinários e ferramentas manuais de marcenaria (figura 2). 
c) Etapa de montagem: Na etapa de montagem, foi possível uma melhor compreensãodas possibilidades que a matéria-prima oferece, bem como desenvolver as habilidades no âmbito da marcenaria.

d) Acabamento: O acabamento foi feito através do lixamento do protótipo já montado, e em seguida foi aplicado Stain a base d'água.

\section{RESULTADOS E DISCUSSÕES}

Como resultados destacam-se os seguintes aspectos: a) Caracterização dos materiais; b) Processo de desenvolvimento de projeto que compreende definição de diretrizes, modelos em escala reduzida, sketches, renders manuais e modelagem paramétrica; c) Processo de produção dos protótipos - Protótipo 1 "Cubo" e protótipo 2 "Costanola".

\subsection{Caracterização dos materiais}

Foi elaborada uma coleta de dados com o objetivo de mensurar e caracterizar as peças de costaneira disponíveis para a pesquisa. Sendo assim, sua estrutura foi dividida em: número de identificação; medidas de comprimento e a largura de ambas as extremidades da peça; defeitos apresentados devido à presença de brocas e cupins comumente encontrados nesse subproduto; características de empenamento e variação dimensional; epossíveis observações que poderiam de alguma forma atrapalhar o beneficiamento secundário do material, como pregos e arames que danificariam os equipamentos (figura 3).

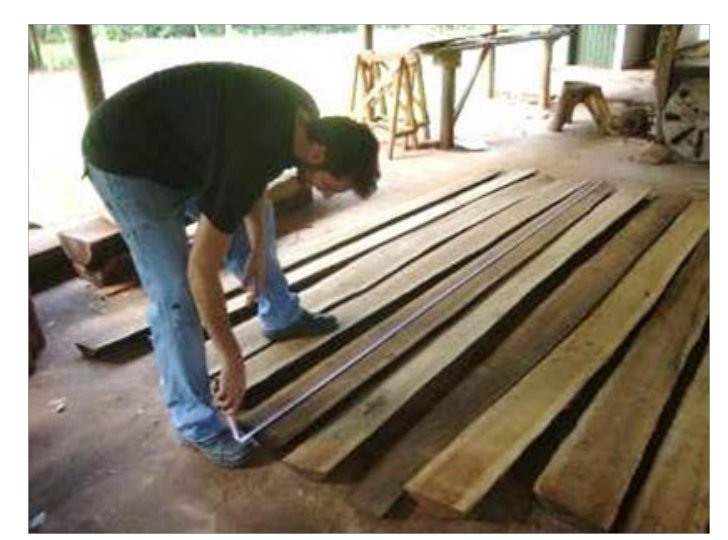

Figura 3- Caracterização das costaneiras.

Fonte: Elaborado pelo autor, com base na pesquisa realizada.

\subsection{Processo de desenvolvimento de projeto}

Após acaracterização do material, foram definidas as diretrizes para a produção dos protótipos. São elas: a) Utilização eficiente do recurso local da madeira serrada de eucalipto da espécie Corymbia citriodora; b)Desenvolvimento de diversas propostas utilizando a costaneira; c) Máxima utilização dos recursos renováveis disponíveis; d) Design atemporal baseado em formas puras e geométricas; e) Mobiliário de alta durabilidade e elevada resistência às intempéries; f) Mobiliário com relativa facilidade de produção com equipamentos básicos de marcenaria; g) Acabamento superficial com produtos à base d'água e; h) Qualificação de espaço público.

Procurando desenvolver diferentes propostas para a aplicação da costaneira, foram elaborados estudos com peças em escala reduzida (Figura 4) que permitiram um 
melhor entendimento da ligação entre essas peças e os possíveis cortes de topo e a acabamentos.

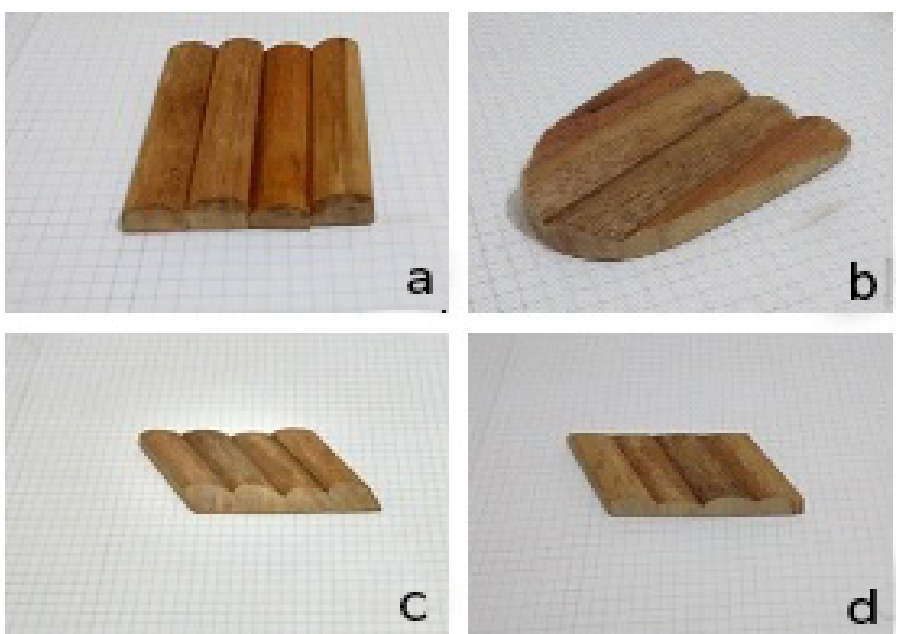

Figura 4- Estudos de cortes de topo em escala reduzida: (a) corte de toporeto $/ 90^{\circ}$, (b) corte de topo eliptico $/ 90^{\circ}$, (c) corte de topo $45^{\circ} / 45^{\circ}$ e(d) corte de topo reto $/ 45^{\circ}$.

Fonte: Elaborado pelo autor, com base na pesquisa realizada.

A etapa de desenvolvimento de sketches foi fundamental para compreender e descobrir as diversas possibilidades de utilizar o subproduto. Para isso, fez-se uso de técnicas livres de desenho com materiais como nankin, lápis de cor e marcadores. Selecionadas as melhores propostas, foram feitos renders manuais (Figura 5) que permitiram uma apresentação mais realista do produto final.
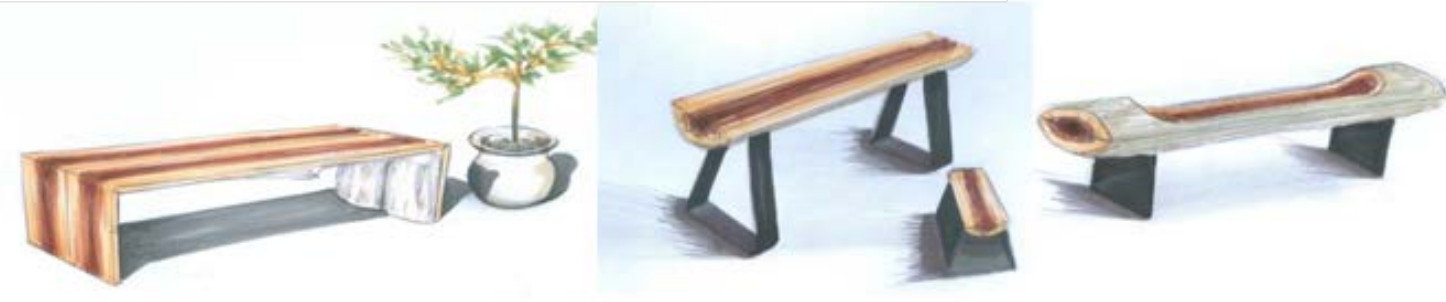

Figura 5- Renders manuais utilizando técnica mista.

Fonte: Elaborado pelo autor, com base na pesquisa realizada.

Visando uma maior precisão na execução dos projetos dos protótipos, utilizouse o softwareSolidWorks 2013 para modelagem paramétrica (Figura 6). O software também permitiu a geração de projetos pré-executivos que guiaram toda a etapa de produção das peças e construção dos protótipos.
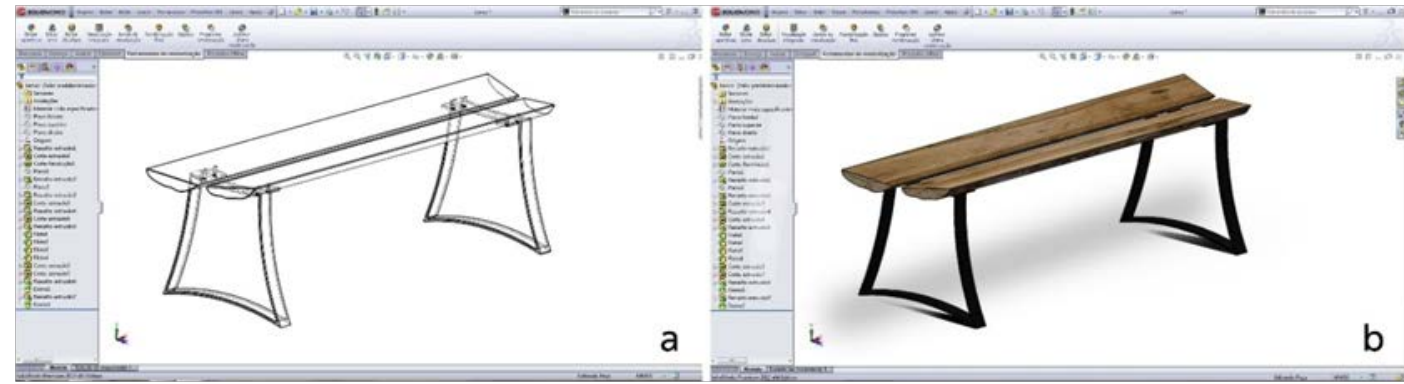

Figura 6- Modelagem paramétrica do protótipo(a) e renderização virtual (b).

Fonte: Elaborado pelo autor, com base na pesquisa realizada. 


\subsection{Processo de produção dos protótipos}

Durante a pesquisa, foram produzidos dois protótipos de mobiliários urbanos empregando a costaneira como matéria prima e seguindo as diretrizes definidas no processo de projeto.

\section{PROTÓTIPO 1 - “Cubo”}

Através da aplicação de técnicas tradicionais de marcenaria, as peças de costaneira foram devidamente esquadrejadas para que pudessem ser unidas por meio de cavilhas para a formação de faces (Figura 7).
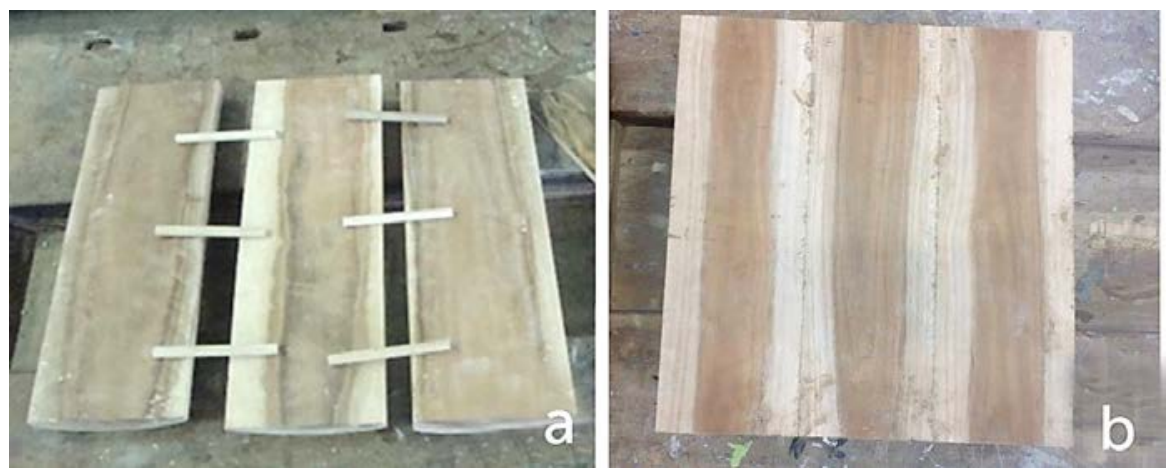

Figura 7- Simulação do posicionamento das cavilhas entre as peças de costaneira (a) e a face formada (b).

Fonte: Elaborado pelo autor, com base na pesquisa realizada.

Em seguida, com as quatro faces formadas, foram feitos cortes de $45^{\circ} \mathrm{em}$ cada uma das peças a fim de garantir o travamento e o posterior acabamento. Terminada a etapa de corte, foi feita a construção do cubo (Figura 8)
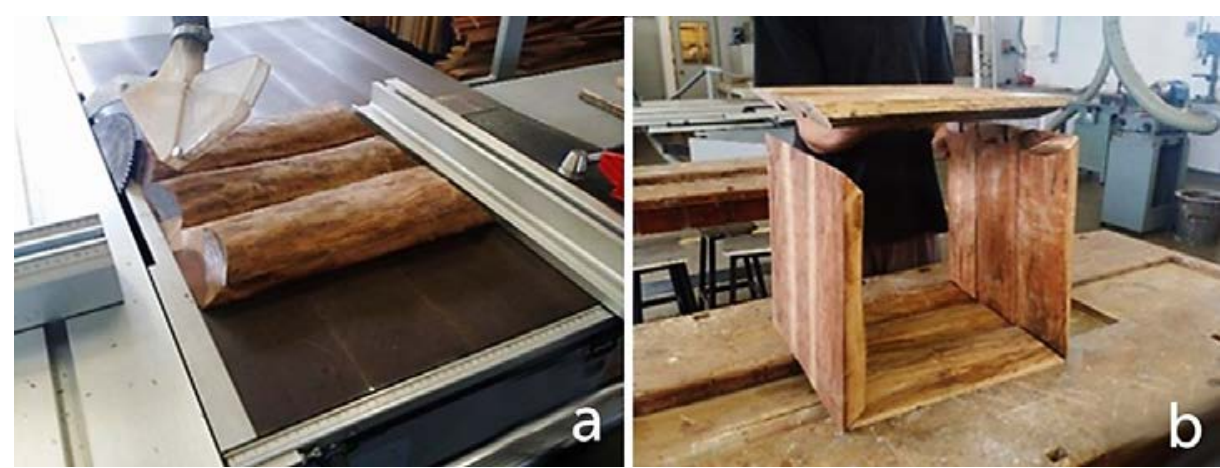

Figura 8 -Corte em $45^{\circ}$ das peças(a) eposicionamento das facesdo cubo (b).

Fonte: Elaborado pelo autor, com base na pesquisa realizada.

A montagem final (Figura 9) foi feita com parafusos autoatarraxantes que garantiram a firmeza e o acabamento adequado do protótipo. Para permitir uma maior praticidade do mobiliário, foram instaladas rodas de silicone devidamente posicionadas a fim de conferir uma qualidade estética ao protótipo final. Por fim, foi feito o acabamento superficial com lixas e aplicação de Stain a base d'água que oferecem maior proteção, durabilidade e acabamento satisfatório. 

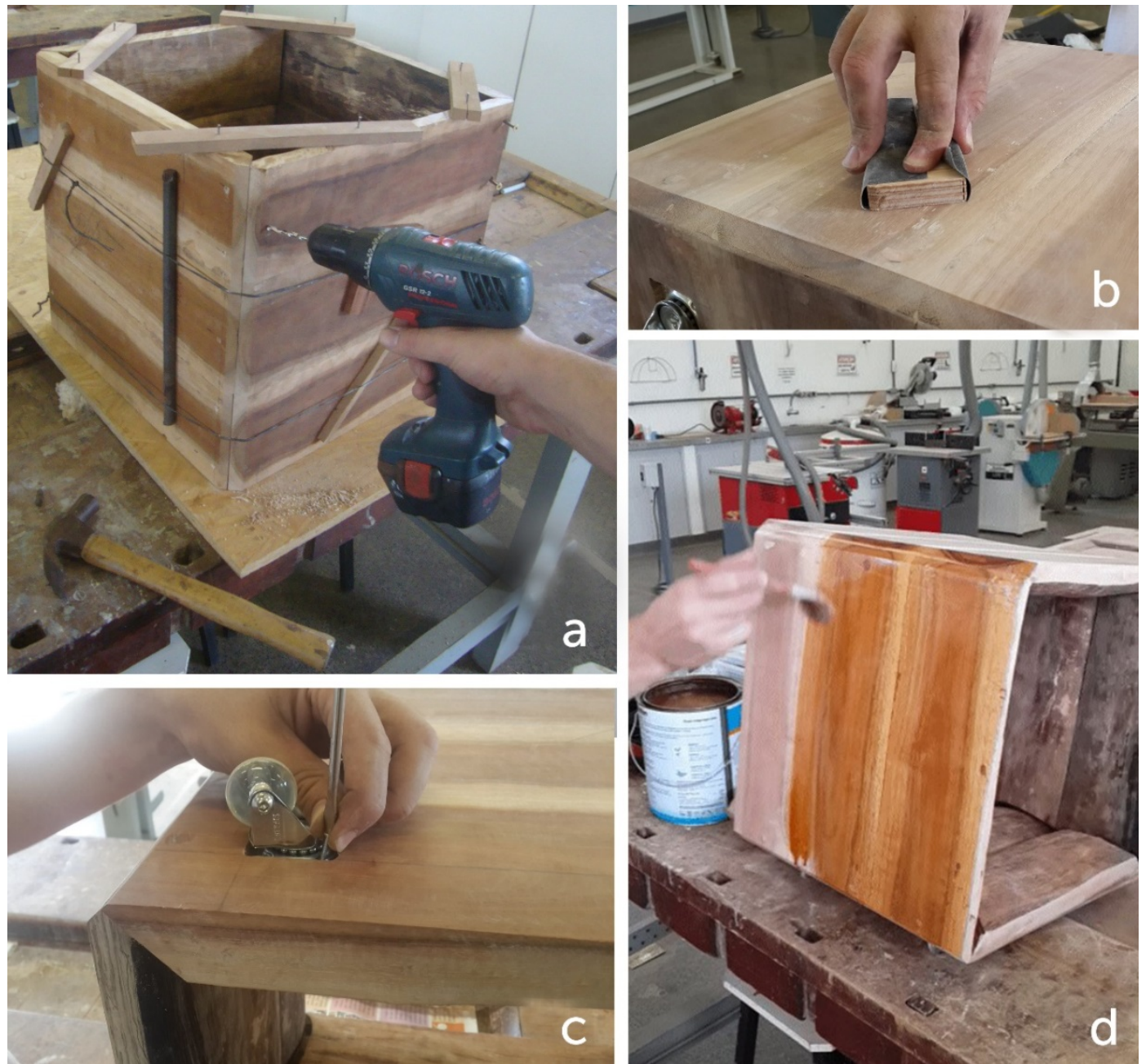

Figura 9- Montagem do cubo com parafusos autoatarraxantes (a),instalação das rodas de silicone (b),lixamento (c) e aplicação deStain(d).

Fonte: Elaborado pelo autor, com base na pesquisa realizada.

Abaixo (Figura 10), o protótipo "Cubo" finalizado.

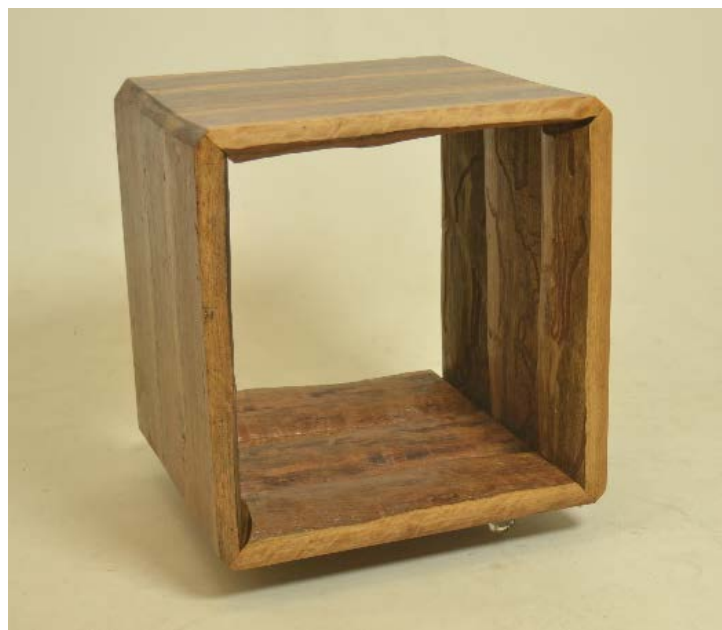

Figura 10- Protótipo Cubo em estúdio fotográfico.

Fonte: Elaborado pelo autor, com base na pesquisa realizada. 


\section{PROTÓTIPO 2 - “COSTANOLA”}

O modelo "Costanola" foi desenvolvido com a proposta de ser um banco modular, com assento feito de costaneiras e pés com feixes de molas de caminhão. Ambos os materiais (costaneiras e molas) são comumente descartados pelas indústrias moveleira e automotiva. O mobiliário apresenta um desenho atemporal e alta resistência, uma vez que foi feito para ser utilizado em áreas abertas estando sujeito as intempéries. Assim como o protótipo "Cubo", o Banco "Costanola" também passou por todas as etapas de desenvolvimento e coletas de dados.

Inicialmente foram construídas as estruturas do banco (pés) (Figura 11) com as molas selecionadas. Diferente do protótipo anterior, esse modelo contou com a utilização de maquinário e técnicas de serralheria.
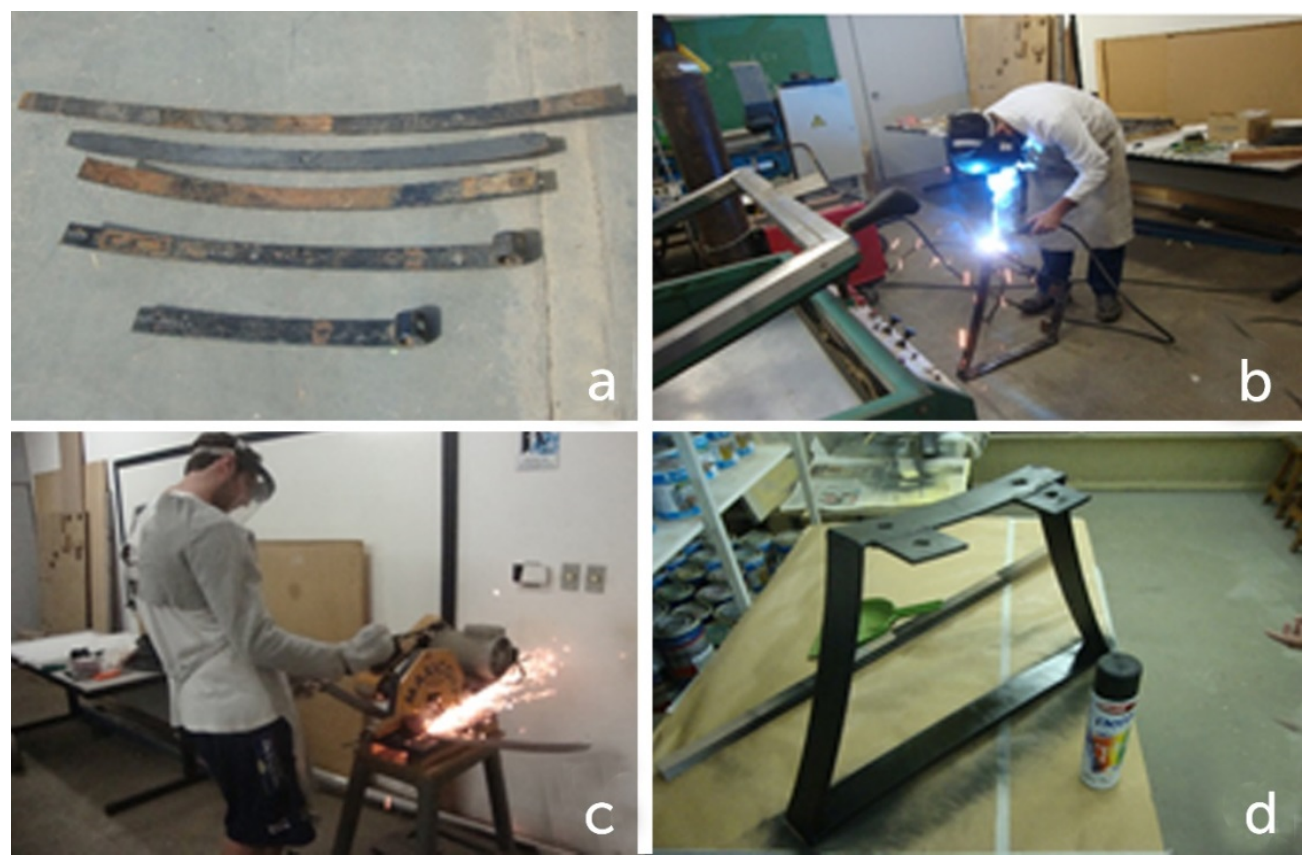

Figura 11- Molas selecionadas (a), soldagem da estrutura (b), corte do excedente (c) e acabamento com esmalte sintético (d).

Fonte: Elaborado pelo autor, com base na pesquisa realizada.

As peças do assento foram trabalhadas seguindo o plano inicial de projeto. Dessa maneira, as duas peças de costaneira utilizadas como assento foram esquadrejadas, cortadas, furadas e lixadas para a construção final do protótipo (Figura 12). 

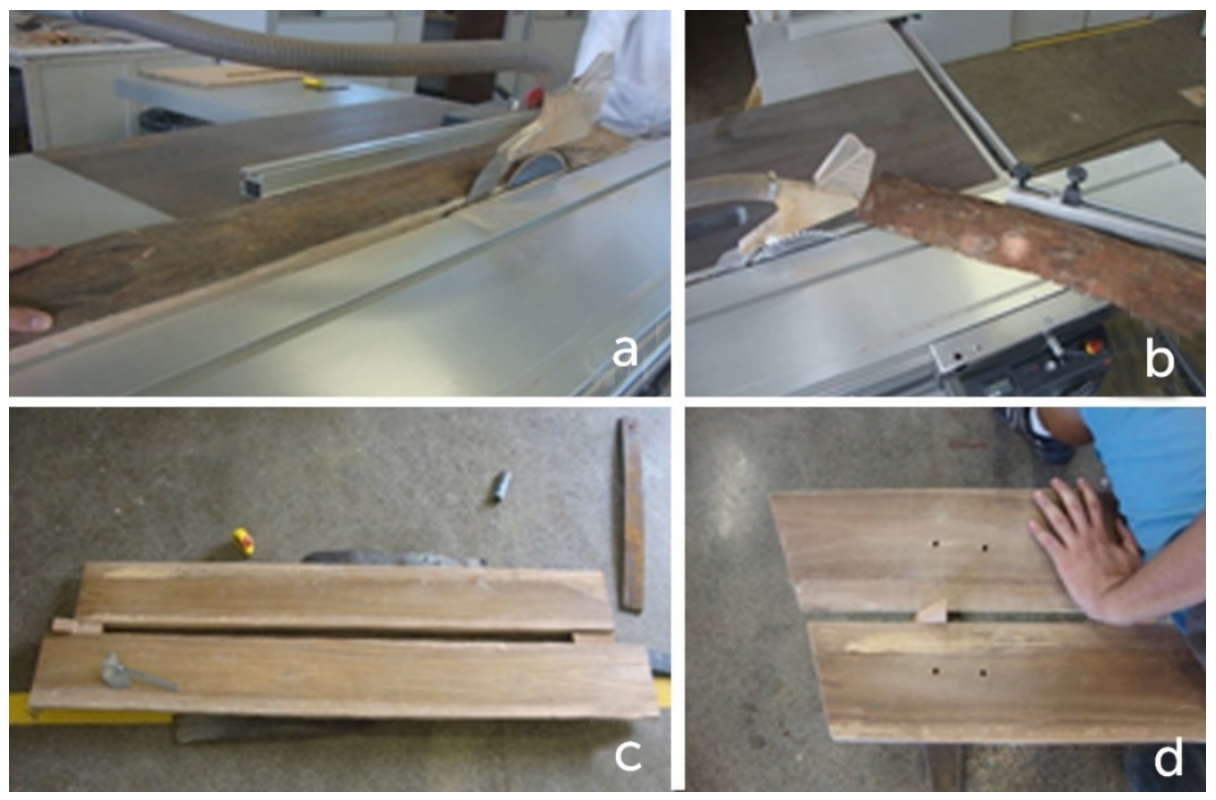

Figura 12-Corte longitudinal (a), corteem ângulo (b), posicionamento das peças (c) e pré-montagem do assento na estrutura (d). Fonte: Elaborado pelo autor, com base na pesquisa realizada.

A construção final do protótipo foi feita com parafusos do tipo cabeça francesa, que uniram as peças do assento com a estrutura dos pés. A montagem conferiu ótimo travamento. $\mathrm{O}$ acabamento final do protótipo contou com a pintura da estrutura em preto fosco e a aplicação de Stain à base d'água nas peças em madeira. Abaixo, o protótipo "Costanola" finalizado (Figura 13).

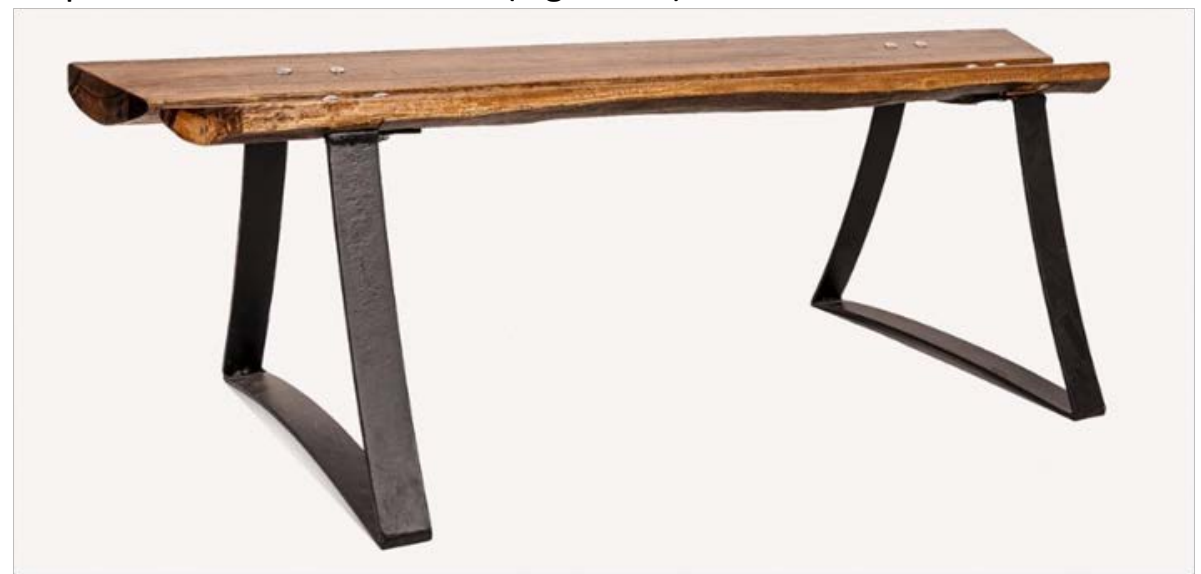

Figura 13- Protótipo “Costanola” finalizado.

Fonte:Elaborado pelo autor, com base na pesquisa realizada.

\section{CONSIDERAÇÕES FINAIS}

Consideramos que os ganhos para o aprimoramento técnico e pessoal foramsignificativos e realmente foi possível praticar os ensinamentos que recebemos em sala de aula eaprofundar o entendimento que design e sustentabilidade são indissociáveis.

Tivemos oportunidade de conhecer projetos correlatos, inclusive fora do país na vigência da BEPE FAPESP (processo no 2015/02589-7); acessar uma bibliografia especializada; exercitar o trabalho em equipe, principalmente na discussão de ideias; 
buscar a integração com profissionais/setores de outras áreas de trabalho; selecionar e planejar os recursos a serem utilizados; rever conceitos e práticas de reciclagem. De fato, foi possível ampliar a visão das oportunidades e também das dificuldades envolvidas nesse tipo de trabalho, justamente porque pudemos "por a mão na massa" e desenvolver um projeto em todas as suas dimensões: operacionais, físicas e sociais.

Pode-se apontar como consideração final o elevado potencial de utilização da "costaneira" para a construção de mobiliários urbanos, tendo como objetivo principal a qualificação de espaços públicos, tais como, praças, jardins, escolas, estações de metrô e ônibus.

Por fim, cabe lembrar que o mobiliário pode assumir o papel de agente social em áreas públicas de convívio familiar, favorecendo o contato com a natureza, práticas de atividades culturais e recreativas, contribuindo para tornar as cidades mais sustentáveis, social e ecologicamente equilibradas.

\section{REFERÊNCIAS}

GIL, E. A. B.O banco público - significado e importância deste equipamento no espaço público. Dissertação de mestrado. FBA, 2011.

FERRÃO, P. Ecologia Industrial: Princípios e ferramentas. Lisboa: Editora:IST Press, 2009. International Council of Societies of Industrial Design. Definitionof Design. Disponível em: <http://www.icsid.org/about/about/articles31.htm>

MANZINI, E.; VEZZOLI, C. O Desenvolvimento de Produtos Sustentáveis: os requisitos ambientais dos produtos industriais. São Paulo: EDUSP, 2002.

PAZMINO, A.V. Uma reflexão sobre Design Social, Eco Design e Design Sustentável. In: I Simpósio Brasileiro de Design Sustentável. Anais... Curitiba, 2007. 